\title{
Identificando atividades de design na educação básica por meio do método Card Analysing
}

\author{
Identifying design activities in basic education through the Card Analysing method \\ Aline D. Bertoldi, Monica C. Possel, Rafael Daron, Renato C. T. Costa, Silvana de Borba
}

educação através do design, atividades de design, card analysing

\begin{abstract}
Habilidades relacionadas ao processo de design - como observação, desenho, criação, prototipação, entre outras - são importantes para todos os cidadãos no contexto da sociedade criativa. O objetivo deste estudo foi analisar como estas habilidades estão sendo ensinadas pelos professores e assimiladas pelos alunos de escolas de ensino médio e fundamental. As atividades de design foram identificadas por meio do Card Analysing, método de pesquisa desenvolvido pelos autores. Como resultado da análise, observou-se um uso inconsciente e ainda básico destas atividades nas escolas.
\end{abstract}

education through design, design activities, card analysing

Skills related to the design process - such as observation, drawing, creating, prototyping, among others - are important for all citizens in the context of creative society. The aim of this study was to analyze how these skills are being taught by teachers and assimilated by the students of primary and secondary schools. The design activities were identified through Card Analysing, a research method developed by the authors. The results of the analysis found an unconscious and basic use of these activities at schools.

\section{Introdução}

A educação básica, nas escolas de ensino médio e fundamental, não acompanhou as modificações ocorridas na sociedade e manteve-se no modelo educacional similar ao do período histórico da revolução industrial. A maioria das escolas não ensina aos alunos as habilidades necessárias para viver neste novo contexto, na sociedade da informação. Segundo Resnick (2002), a criatividade é uma das habilidades mais importantes que devem ser alimentadas e desenvolvidas nos alunos e, por isto, prefere denominar a sociedade da informação de sociedade criativa. O uso de métodos estáticos de ensino não estimula o desenvolvimento dos interesses e capacidade de criação dos alunos e não permitem a eles a oportunidade e o interesse de aprimorar seu pensamento crítico. As características mais cultivadas no atual ensino têm sido a obediência, passividade e dependência e, por este motivo, torna-se imperativo a descoberta de novas formas de ensinar, que estimulem os alunos a serem investigadores e criadores do conhecimento, principal ativo da economia atual (Meyer \& Rosa, 2003). As exigências já não são mais estáticas e cada vez mais, surgem novas áreas de conhecimento que requerem o desenvolvimento de capacidades criativas. É importante que se estimule estudantes a realizarem atividades que os permitam solucionar problemas e, a partir disto, explorar o mundo que os cercam.

Por isso, por meio deste estudo em quatro escolas de ensino médio e fundamental, buscou-se identificar como são desenvolvidas as atividades pedagógicas que estimulam estas habilidades. Entre as atividades pedagógicas que estimulam habilidades para a sociedade criativa estão as atividades de design. Para Fontoura e Pereira (2004), as atividades de design "permitem à criança aprender a solucionar problemas e explorar o mundo de forma mais espontânea, livre e flexível". Para alcançar o objetivo proposto pelo estudo, foi desenvolvido um método de pesquisa que pudesse auxiliar o reconhecimento das atividades de design desenvolvidas em sala de aula pelos professores e alunos, muitas vezes realizadas de modo inconsciente. Este método, nomeado pelos autores de Card Analysing, ajuda na identificação das oportunidades de aprendizagem por meio das atividades de design e na caracterização da maneira como elas ocorrem nas escolas. 
Utilizar as atividades de design no ensino significa explorar as capacidades de desenhar, transmitir, adquirir, construir e reconstruir, utilizar, entender e compreender (Fontoura \& Pereira, 2004). Isto permite aos estudantes desenvolver a consciência de que existem caminhos que a mente percorre ao deparar com um problema, e a solução surge naturalmente quando as habilidades pertinentes às atividades de design são estimuladas (Fontoura, 2002). Atividades de design facilitam o afloramento das habilidades necessárias para o desenvolvimento de projetos, sejam eles de produto, gráfico, entre outros. Aprendê-las de forma a se tornarem um procedimento natural traz à pessoa a capacidade de encontrar uma solução para um problema de forma criativa. Acredita-se que é excepcional aos estudantes serem estimulados para a prática dessas atividades enquanto estão no ensino médio e fundamental, pois design não está estritamente em uma formação profissional, mas sim no dia-a-dia de qualquer pessoa, seja ela designer ou não.

\section{Aplicação do Card Analysing}

O desenvolvimento do método Card Analysing foi desencadeado a partir de uma reflexão sobre como os alunos da atualidade são educados e a existência de estímulos à criatividade suportados pelas atividades de design, ou seja, como ocorre o ensino nas escolas e como os alunos são estimulados a construir o conhecimento. O Card Analysing foi desenvolvido pelos autores na disciplina de Metodologia de Pesquisa em Design no curso de pós-graduação em Design de Interação. Após algumas pesquisas preliminares com alunos de ensino médio, observou-se a necessidade de um método mais coerente e específico para o tipo de estudo sendo realizado. Dentre os métodos já existentes analisados e testados, o Card Sorting foi o que serviu como inspiração e base para o surgimento do Card Analysing. O Card Sorting constitui na aplicação de cartões com palavras diversas escolhidas através de uma análise para compor a nomenclatura de um determinado sistema, produto ou serviço.

Embora a criação do Card Analysing tenha sido inspirada pelo Card Sorting, dele manteve-se apenas o formato de cartões e a possibilidade do participante renomeá-los. No Card Analysing, os cartões são constituídos de habilidades relacionadas às atividades de design. Estes são apresentados em conjunto para o participante selecionar as habilidades pertinentes às suas atividades escolares, ordenando-os de forma lógica ou aleatória, permitindo também aos participantes renomear os cartões de acordo com sua experiência e conhecimento sobre as atividades de design. O conjunto é composto por vinte habilidades relacionadas às atividades de design: "adaptar", "analisar", "aplicar", "combinar", "comparar", "conceituar", "construir", "criar", "desenhar", "estruturar", "interpretar", "melhorar", "observar", "pesquisar", "planejar", "projetar", "prototipar", "refletir", "relatar" e "solucionar". Estas habilidades foram escolhidas dentre as cinquenta habilidades operativas listadas por Antunes (2001) que foram consideradas as mais relacionadas com as atividades de design.

Cada um dos vinte cartões contêm uma habilidade escrita e espaço para o preenchimento livre das respostas (figura 1). Além disto, foram apresentados dez cartões em brancos para 0 participante acrescentar alguma habilidade que estivesse mais familiarizado e não listada dentre as vinte apresentadas. Caso algum participante demonstrasse dúvida sobre o significado das habilidades uma definição previamente elaborada era lida para o participante. Os cartões foram apresentados a dois grupos de participantes: alunos e professores. Com a intenção de auxiliar o preenchimento dos cartões, foi apresentada aos participantes a seguinte instrução: "Escolha cinco habilidades dentre as quais você tem maior familiaridade e cite um exemplo de como você a tem praticado." A forma de preenchimento ficou aberta, possibilitando ao participante completar os cartões com substantivos, desenhos, colagens, brincadeiras e outros. 
Figura 1: Cartões em vista de frente.

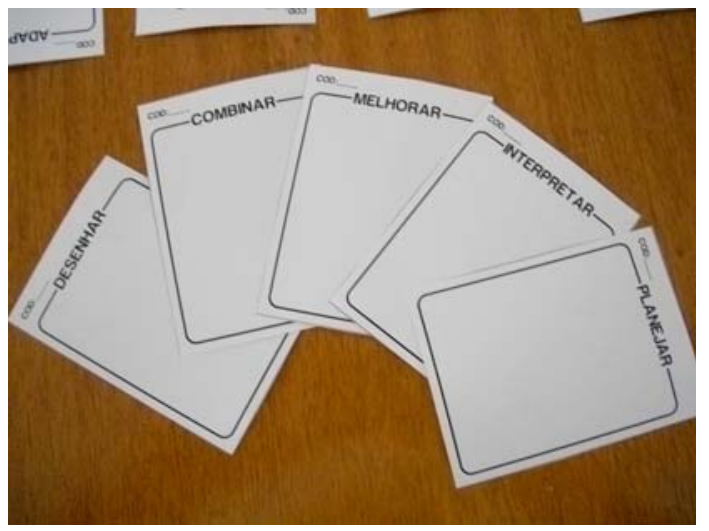

\section{Resultado: as habilidades mais trabalhas na atividades de design}

A maioria dos participantes optou por completar os cartões na forma escrita. As cinco habilidades mais escolhidas foram: "pesquisar", "interpretar", "observar", "desenhar" e "planejar". O termo "prototipar" não foi escolhido por nenhum participante. Percebeu-se que as habilidades são estimuladas pelos professores por meio de tarefas escolares que propõe uma atividade de design indiretamente. Um dos alunos participantes citou a elaboração de uma maquete ao escolher a habilidade "projetar". Ao elaborar a maquete, o participante relatou que precisou pesquisar as informações para o entendimento do tema e utilizar um desenho como guia na construção da mesma (figura 2).

Figura 2: Exemplos de cartões preenchidos.
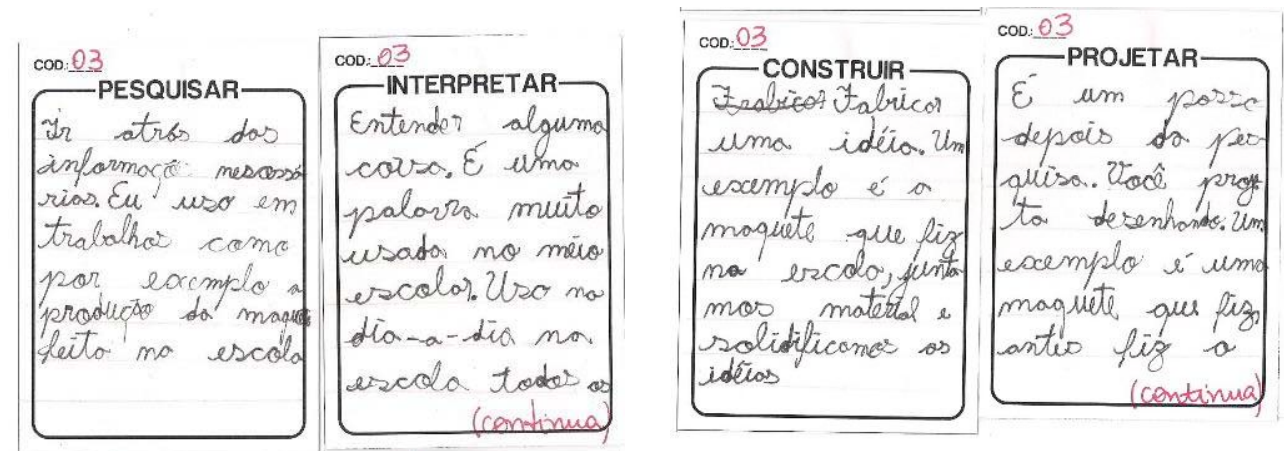

Um outro exemplo citado por um aluno foi um trabalho sobre globalização e sustentabilidade solicitado pelo professor de geografia. Este participante escolheu a habilidade "melhorar" para relatar a experiência de fazer uma pré-apresentação ao professor, que o aconselhou a melhorar em alguns aspectos do trabalho. Após concluir o trabalho com as sugestões do professor, apresentou a versão final e obteve uma nota superior em relação à sua primeira apresentação. Outra habilidade escolhida por um aluno foi "combinar", utilizada na aula de artes, quando foi solicitado para a combinação de cores primárias para formar cores secundárias. O professor apresentou as cores primárias, explicou sobre as secundárias, porém não informou qual combinação de cores formaria a nova cor, estimulando assim a capacidade de observação e análise dos estudantes.

Foi escolhida também a habilidade "planejar" que, segundo o participante aluno, é utilizada em qualquer trabalho solicitado pelo professor. Relacionou a palavra "planejar" com "imaginar" explicando que, ao ser questionado sobre alguma atividade, primeiro imagina as suas idéias,depois desenha para torná-las tangíveis. Também relatou que, planeja as datas de encontros com os integrantes da equipe para o desenvolvimento do trabalho. Já a habilidade "pesquisar" se mostrou interligada com quase todas as atividades solicitadas pelos professores, em especial com os trabalhos escritos ou apresentação oral em sala de aula. Um aluno que relatou sobre esta habilidade exemplificou com uma atividade passada pelo professor de 
geografia, que solicitou uma pesquisa sobre dez termos pertinentes ao contexto da disciplina, como serrado, florestas, relevo, vegetação etc. Como resultado, os alunos apresentariam suas conclusões sobre os assuntos pesquisados, oralmente.

Entre os participantes alunos, a habilidade mais lembrada foi "interpretar", com 16\%, pois é comum sua utilização na disciplina de português como meio de entendimento dos textos. A habilidade "pesquisar" foi citada por $12 \%$ dos alunos, enquanto "melhorar", "solucionar", "desenhar" e "observar" foram as terceiras mais citadas (figura 3).

Figura 3: Resultados dos participantes alunos.

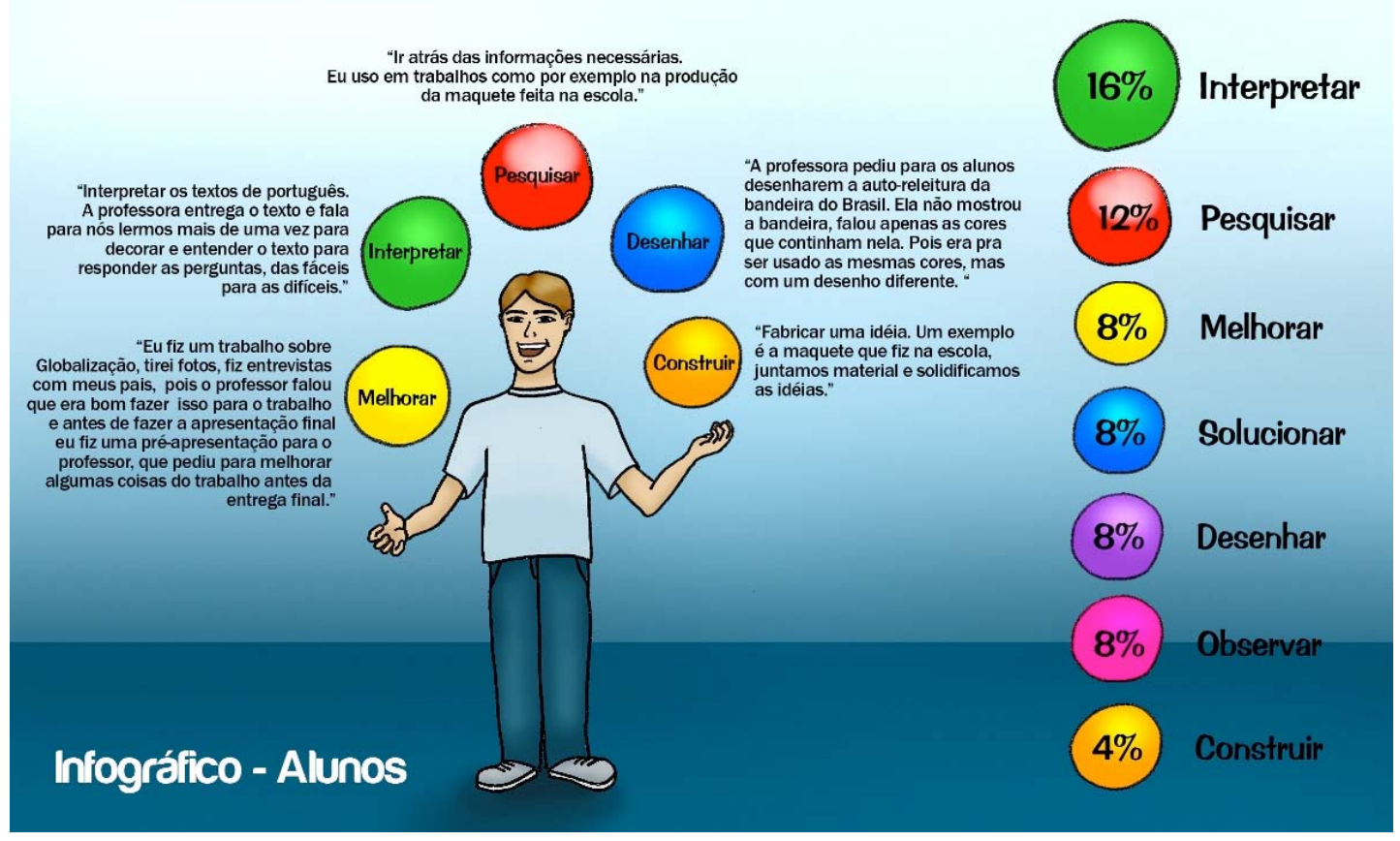

Em comparação com os participantes alunos, verificou-se a diferença na escolha das habilidades pelos participantes professores. Um participante professor selecionou a habilidade "relatar" e exemplificou sua utilização em uma atividade com os alunos após uma visita a Festa das Flores - festa típica da cidade de Joinville - que solicitava a elaboração de um texto sobre a experiência de visitar o evento, estimulando assim a capacidade dos alunos de observação, análise e crítica. Outra habilidade citada a "criar", estimulada nos alunos por meio de atividades de interpretação de textos e redação de contos próprios. Outro professor, que leciona a disciplina de língua portuguesa e literatura, mencionou que utiliza muitas das habilidades apresentadas para auxiliar no ensino. Como exemplo, solicitou aos alunos que desenhassem uma história em quadrinhos estruturando-as a partir de situações vividas por eles no dia-a-dia. A produção de textos para estas histórias em quadrinhos, também foi incentivada por ele, apoiada na reflexão e interpretação de textos e charges.

Os professores escolheram algumas habilidades para explicar atividades que fazem parte da rotina docente. Uma delas foi "adaptar", utilizada por um professor de educação física para adequar modalidades de jogos em novas atividades físicas. Esta mesma habilidade foi utilizada também por um professor de biologia que relatou sobre a adaptação de assuntos teóricos em atividades práticas. Por exemplo, em uma aula sobre fungos, apresentou o conteúdo e depois foi a campo com os alunos, estimulando a capacidade de visualizar e identificar as formas reais de vida da natureza. Ainda, foram citadas as habilidades "planejar" e "projetar", utilizadas na preparação das aulas - que permitem a futura verificação do alcance dos objetivos e avaliação dos aspectos a serem melhorados - e no próprio andamento delas.

Verificou-se que, dentre todas as habilidades escolhidas no grupo de professores, a habilidade "planejar" foi selecionada 10\% dos participantes. As habilidades "observar", "refletir", "pesquisar", "criar", "adaptar" e "desenhar" foram as segundas mais citadas, cada uma correspondeu a $8 \%$ do total de respostas (figura 4). 
Figura 4: Resultados dos participantes professores.

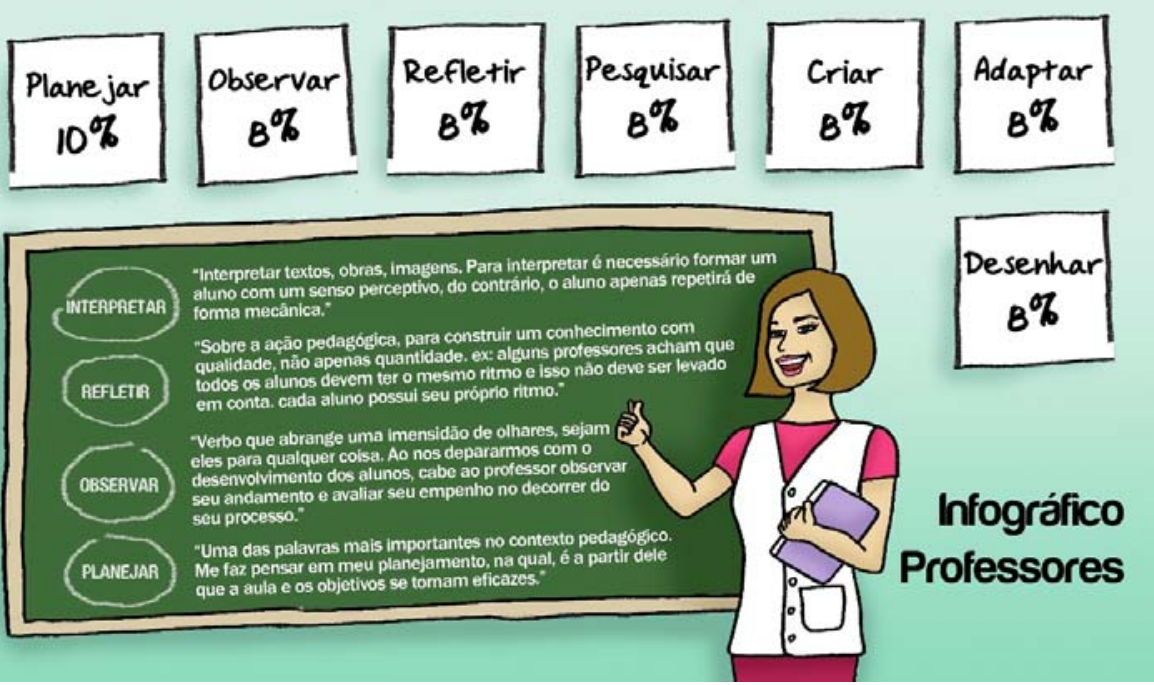

\section{Considerações finais}

Com esta pesquisa foi observado que as atividades de design estão presentes nas escolas estudadas, porém, são desenvolvidas de forma inconsciente na maioria dos casos, tanto pelos professores, quanto pelos alunos. Por exemplo, num primeiro momento, quando um trabalho é solicitado aos alunos, eles recorrem à imaginação para projetar suas idéias, após isso, passam pelo desenho a mão, alguns indo já para a forma final, pulando algumas atividades que poderiam auxiliar na hora do desenvolvimento, outros com rascunhos, e chegando até o objetivo final, imaginado, pensado, criado por eles. Poucos participantes alunos relataram que essas atividades eram solicitadas pelos professores e a maioria relatou que as realizavam conforme viam a necessidade. Outros não conheciam estas possibilidades, considerando-as relevantes para o desenvolvimento dos trabalhos escolares. Em resumo, as atividades de design auxiliam as aulas, mas como não são de conhecimento de todos perde-se o potencial de estímulo a criação e inovação.

Com relação aos professores, percebeu-se que as vinte habilidades relacionadas são estimuladas nos alunos, porém, são pouco voltadas a criação e inovação. Observou-se também que os professores utilizam as habilidades no desenvolvimento das suas aulas, apesar de não as perceberem como processo criativo e de inovação na forma e metodologia de ensino. Poucos pensaram no design como parte integrante do projeto de novas aulas, que possam também oferecer aos seus alunos a capacidade de criar e desenvolver por meio do design. Constatou-se que o interesse dos professores em utilizar as atividades de design é deficiente, possivelmente devido à forma como estes foram educados. Alguns se sentem relutantes em relação ao desenvolvimento das capacidades criativas, pois alegam que, ao estimular a criatividade e as atividades de design, deve-se levar em conta as capacidades individuais de cada aluno.

Por fim, considerou-se o Card Analysing como um método eficaz para avaliar a utilização das atividades de design nas escolas pesquisadas. Os autores acreditam que sua utilização possa ser extrapolada para qualquer escola de ensino médio e fundamental.

\section{Agradecimento}

Agradecemos aos alunos e professores da Escola Municipal João de Oliveira, Joinville, SC; Escola Municipal Profa Zulma do Rosário Miranda, Joinville, SC; Escola Estadual Giovani Trentini, Rio dos Cedros, SC; e Colégio Estadual Cely Terezza Grezzana, Chopinzinho, PR, que se disponibilizaram a participar desta pesquisa. Agradecemos também ao Instituto Faber-Ludens por proporcionar atividades de design que estimularam nossa criatividade e a capacidade de pensar "projetualmente". 


\section{Referências}

ANTUNES, C. 2001. Trabalhando habilidades: construindo idéias. São Paulo: Scipione.

FONTOURA, A. M. 2002. EdaDe: a educação de crianças e jovens através do design. Tese (Doutorado) - Departamento de Engenharia de Produção, Universidade Federal de Santa Catarina, SC.

FONTOURA, A. M.; PEREIRA, A. T. C. 2004. A criança e o design: aprender brincando. Anais do 6ํㅡㄹ Congresso Brasileiro de Pesquisa e Desenvolvimento em Design. São Paulo: FAAP, 323329.

MEYER, G. C.; ROSA, S. B. 2003. Design na escola. Anais do $2^{\circ}$ Congresso Internacional de Pesquisa em Design. Rio de Janeiro: CIPED.

RESNICK, M. 2002. Rethinking Learning in the Digital Age. In: Kirkman G. (Ed.) The Global Information Technology Report: Readiness for the Networked World. New York: Oxford University Press.

SPENCER, D. 2009. Card sorting: designing usable categories. New York: Rosenfeld Media.

\section{Sobre os autores}

Aline Dayanna Bertoldi, Especialista em Design de Interação, Instituto Faber-Ludens; Bacharel em Projeto de Produto, Univille; Técnica em Desenvolvimento de Produtos pela ETT.

a.ninis@gmail.com

Monica Cristina Possel, Especialista em Design de Interação, Instituto Faber-Ludens; Bacharel em Design com habilitação em Programação Visual, Univille.

monicapossel@gmail.com

Rafael Citadella Daron, Especializando em Design de Interação, Instituto Faber-Ludens; Bacharel em Sistemas de Informação, Unisep.

rafaeldaron@gmail.com

Renato da Cunha Tardin Costa, Mestrando em Design, UFPR; Especialista em Ergodesign e Avaliação de Interfaces, Puc-Rio; Bacharel em Desenho Industrial, Esdi/Uerj. rctcosta@gmail.com

Silvana de Borba, Bacharel em Projeto de Produto, Univille. sissiborba@gmail.com 